\title{
Geographic distribution, host plants, and morphological variation of the currently radiating phytophagous ladybird beetle Henosepilachna diekei
}

Kei W. Matsubayashia ${ }^{a}$ Sih Kahono ${ }^{b}$, Naoyuki Fujiyamac, Jun Yokoyamac, Sri Hartini ${ }^{b}$, Suranga Basnagalad, Yaowaluk Monthume, Rosli Hashim ${ }^{\mathrm{f}}$ and Haruo Katakurag

aDepartment of Animal and Plant Science, The University of Sheffield, Sheffield, UK; 'Boology Division, Research Centre for Biology, Indonesian Institute of Science - LIPI, Cibinong, Indonesia; 'Department of Biology, Faculty of Science, Yamagata University, Yamagata, Japan; dDepartment of Entomology, Horticultural Crops Research \& Development Institute (HORDI), Gannoruwa, Sri Lanka; 'Department of Marine Science, Faculty of Fisheries, Kasetsart University, Chatuchak, Thailand; Institute of Biological Science, University of Malay, Kuala Lumpur, Malaysia; ${ }^{\circ}$ Department of Natural History Sciences, Faculty of Science, Hokkaido University, Sapporo, Japan

\begin{abstract}
To overview the morphological and ecological diversification within a species of phytophagous ladybird beetle Henosepilachna diekei, information concerning its distribution and host plant use was studied. This species was found widely in South East and South Asia from the Philippines through the Greater Sunda islands, a western part of Lesser Sundas, the Malay Peninsula to Sri Lanka. Mikania species (Asteraceae), Mikania micrantha in particular, were the most frequently used host plants, but some other plants belonging to Lamiaceae or Acanthaceae were also used by some local populations. Each population is possibly monophagous. According to morphological analyses, seven populations from four host plants at six sites on four Indonesian islands were grouped into two, one occurring on Java and Kalimantan (Borneo) and another on Sulawesi and Lombok, indicating that they were separated by the Wallace line. This morphological distinction was not correlated with the host plant use.
\end{abstract}

\section{ARTICLE HISTORY}

Received 9 October 2014

Accepted 28 July 2015

Online 28 September 2015

\section{KEYWORDS}

Adaptive radiation; Epilachnini; Indonesia; morphological variation; principal component analysis

\section{Introduction}

Rapid lineage diversification in association with evolution of various ecological characters and differential niche utilization is often referred to as "adaptive radiation", which is one of the major processes to generate biodiversity (Schluter 2000). This rapid lineage diversification is often coupled with morphological divergence between geographically, ecologically and phylogenetically distinct populations in single species (Gould and Woodruff 1990). As morphological diversification is often associated with species diversification through 
enhancing reproductive isolation such as lock-and-key (Sota \& Nagata 2008; Sota \& Tanabe 2010; reviewed in Masly 2012) or size assortative mating (Brown 1990; Jiang et al. 2013), the investigation of morphological variation other than ecological characters within currently radiating species is critical to understand the process of adaptive radiation.

Henosepilachna diekei Jadwiszczak \& Węgrzynowicz (referred to as Epilachna sp. 3 in Katakura et al. 2001; see also Kobayashi et al. 2009; for the taxonomic treatment) is a phytophagous ladybird beetle that was described based on specimens from the Philippines (Dieke 1947). In our survey on phytophagous ladybird beetles in South East Asia, this species is also found from various localities in Indonesia and adjacent countries. In addition, there seem to be host races in this species. In Java, for example, there are two types of populations, one depending on Leucas lavandulifolia Sm. (Lamiaceae), and the other on the climbing hemp weed, Mikania micrantha Kunth (Asteraceae) (Katakura et al. 2001; Matsubayashi et al. 2011; Fujiyama et al. 2013). A series of field and laboratory experiments demonstrated that beetle populations from L. lavandulifolia do not grow on M. micrantha and those from M. micrantha do not grow on L. lavandulifolia (Matsubayashi et al. 2011; Nakano unpublished data). In addition, there is no reproductive isolation between these two types of populations except differential host plant use (Matsubayashi et al. 2011, 2013a, 2013b) suggesting that these two types are at the early stage of speciation driven by divergent host adaptation (i.e. "host race", sensu Drès \& Mallet 2002). We have further found that there are populations that show specialization to plants other than $M$. micrantha and L. lavandulifolia (Matsubayashi 2008). Phylogenetic analysis based on partial nucleotide sequences of the mitochondrial cytoplasmic oxidase subunit I (COI) gene revealed that the beetle populations from each host plant are not monophyletic (Fujiyama et al. 2013), indicating that the host shift could occur several times in different localities in Java. Katakura et al. (2001) further observed that the $H$. diekei populations from Sumatra, a neighbouring island of Java, use other host plants belonging to Lamiaceae. Hence, $H$. diekei provides a good example with which to investigate adaptive radiation under various geographic settings. Preliminary morphological observation indicated that there was a certain degree of morphological variation (body shape, elytral spot pattern, minute structure of male genitalia) between populations of $H$. diekei sampled on different host plants.

In this paper, we investigate the distribution and host plants of $H$. diekei in the Asian tropics and further analyse the morphological divergence between geographically and ecologically different populations. Although our preliminary morphological observation indicates some degrees of inter-population morphological variation, it is still unknown whether the morphological divergence is associated with differential host plant use or not. This kind of knowledge is essential to understand the pattern and process of morphological diversification during adaptive radiation.

\section{Material and methods}

\section{Beetle distribution and host plants}

We surveyed the occurrence and host plant use of $H$. diekei from 1980 to 2013 in almost all major islands of Indonesia (Java, Sumatra, Kalimantan, Sulawesi, Bali, 
Lombok, Sumbawa, Flores, West Timor and Papua) and some other localities in South East Asia (the shaded areas in Figure 2). We recorded the absence or presence of the beetle, and if present, we collected the beetles and the host plants for morphological analysis or species identification. Species identification was made based on morphol-

ogies by K. Matsubayashi and H. Katakura for the beetles and by J. Yokoyama for the host plants.

\section{Morphological analysis}

Adult individuals collected were fixed in absolute alcohol and kept at $-40^{\circ} \mathrm{C}$. Six body characteristics (body length, pronotum length, pronotum width, elytral length, elytron width, elytral height; see Figure 1A) were measured using a Nikon SMZ1500 microscope (Nikon Instech, Co., Ltd.) by recording images with a Digital Sight camera system (DS-L1, Nikon Instech, Co., Ltd.). Image stacking for the dorsal and lateral views of habitus was performed with CombineZP (Hadley, 2010; http://www.hadleyweb.pwp.blueyonder.co. $\mathrm{uk} /$ ). Then, males were dissected in distilled water, and genitalia were eviscerated, cleaned in alkali solution $(0.1 \% \mathrm{KOH})$ for 12 hours, and then washed in $0.1 \%$ lactic acid. The number of hairs on the penis guide of the tegmen and the structure of the apical edge of the penis were examined and recorded using the same systems described above (see Figure 1B, C). According to a preliminary observation, the structure of the apical edge of the penis was classified into three types; emarginate (Type I), truncate (Type II) and convex (Type III) (see Figure 6).

Principal component analysis (PCA) was conducted with the six morphological characters using princomp functions in $R$ 2.15.0 software ( $R$ Development Core Team R 2012). After the principal component analysis, we squeezed the principal components based on the importance of components especially for cumulative proportion (in general, more than $80 \%$ is useful). Further, we detected the relative contribution of each morphological character for the selected principal components based on the factor loadings, showing correlation of the factor to the principal components. We then tested statistical differences in the value of selected morphological characters among beetle populations using one-way analysis of variance (i.e. aov function) with subsequent multiple comparisons by Tukey HSD test.

Furthermore, we tested differences in the number of hairs on the penis guide and the types of apical edge of penis among populations using a Kruskal-Wallis test with multiple comparisons by Kruskal.wallis function in $R$ 2.15.0 software.

\section{Results}

\section{Beetle distribution and host plants}

Collection and observation records of Henosepilachna diekei and the host plant use were summarized (Figure 2).

Beetle distribution: Henosepilachna diekei was widely found from the southern part of the Malay Peninsula (Ban Han in Songkhla, Thailand and Kuala Lumpur in Malaysia) through the Greater Sunda Islands (Borneo, Sumatra, Java) to the western part of the Lesser Sunda Islands (Bali and Lombok) (Figure 2). This beetle was also 
A

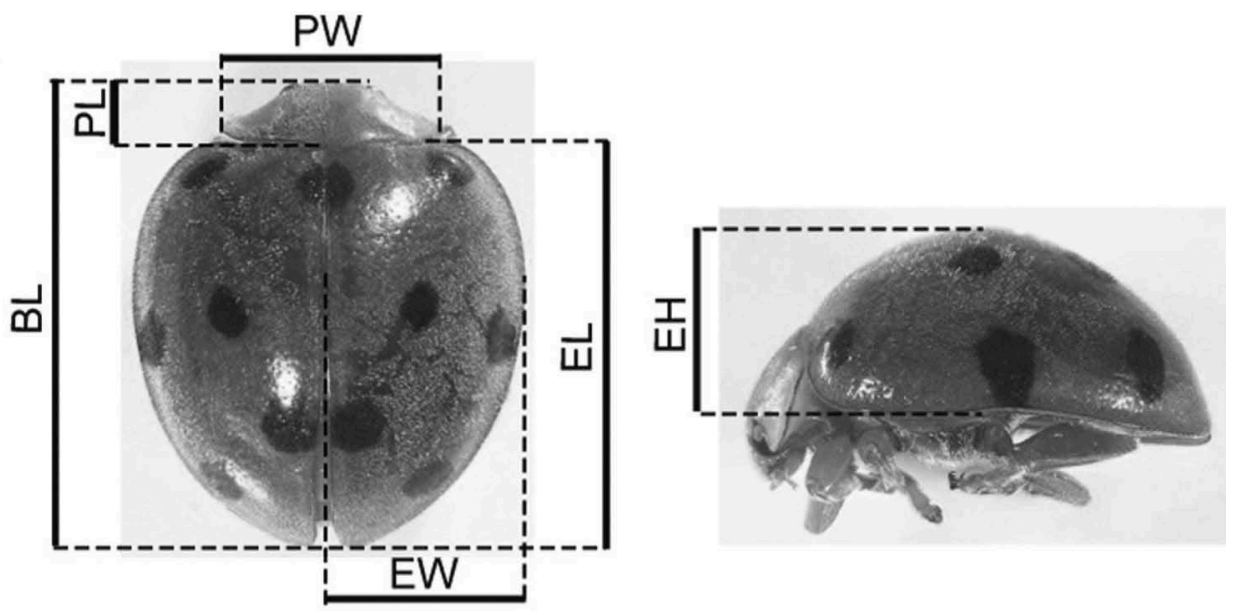

B

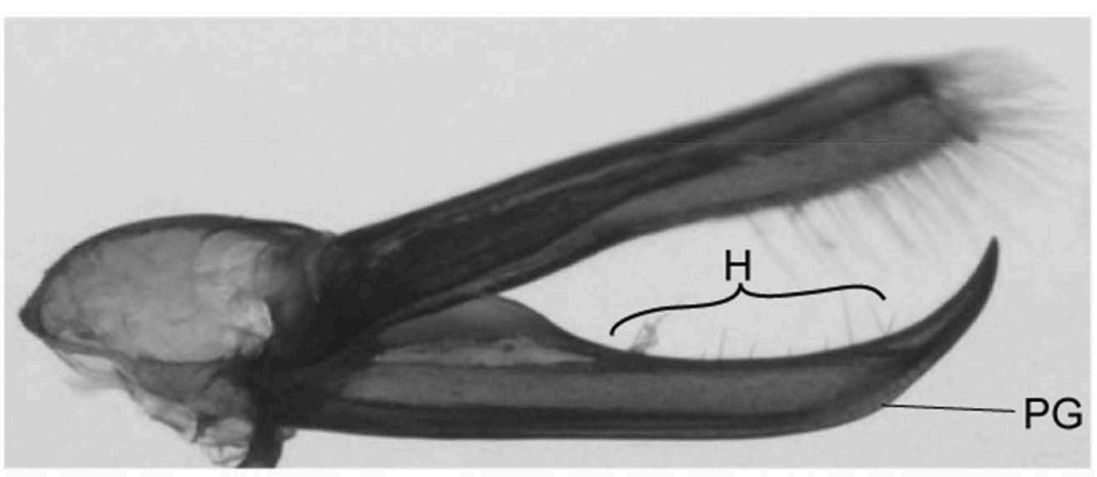

C

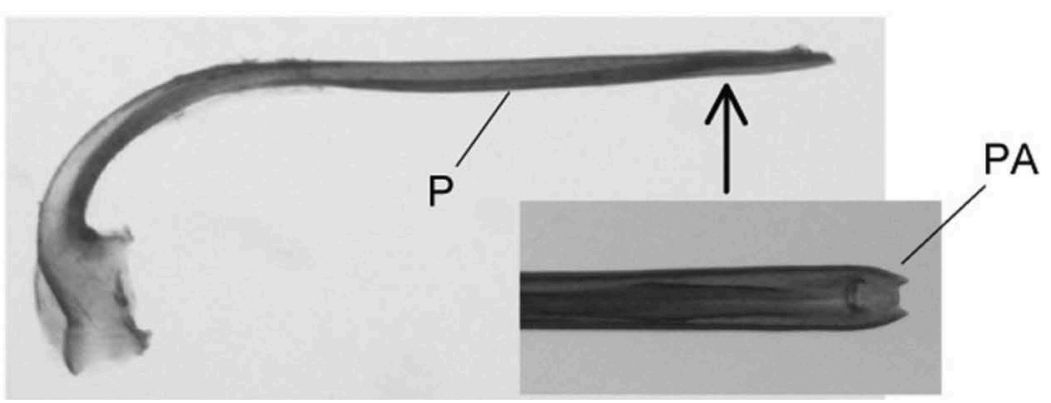

Figure 1. Morphological characters of Henosepilachna diekei measured in the present study. (A) Dorsal and lateral views of habitus with measured body parts; BL, body length; PL, pronotum length; PW, pronotum width; EL, elytra length; EW, elytron width, $E H$, elytra height. (B) Lateral view of tegmen (PA, paramera; $\mathrm{H}$, hair on penis guide; $P G$, penis guide). (C) Lateral view of penis ( $P$, Penis; $P A$, ventral view of apical edge of penis).

recorded from Gannoruwa, Sri Lanka (not shown in Figure 2). On the other hand, this species was not found in the eastern part of the Lesser Sundas (Flores, Sumbawa, West-Timor), Papua, and the southern part of Thailand (excluding the 


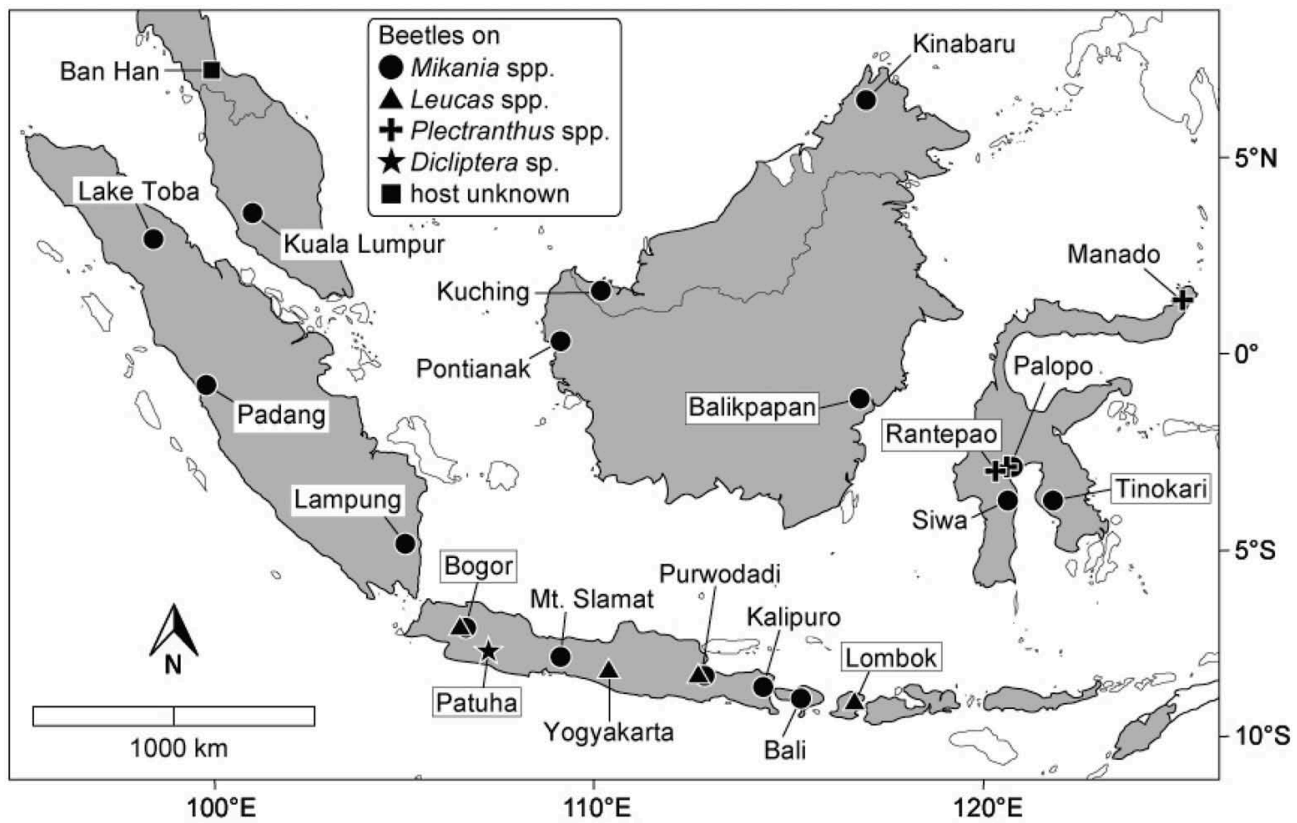

Figure 2. Distribution and host-plant use of Henosepilachna diekei populations in South East Asia. The distribution of $H$. diekei was investigated in shaded islands/regions. Localities where the occurrence of $H$. diekei was observed were shown by the names and symbols for the host plants. Six beetle populations from five localities used for the morphological analysis were black-edged.

southernmost part) in the Malay Peninsula (Figure 2), despite the potential host plants of $\mathrm{H}$. diekei, especially Mikania micrantha, being frequently observed in these areas (see below).

Host plants: Henosepilachna diekei used plants of at least three families and four genera in the area surveyed (Figure 2). Of these four genera, Mikania (Asteraceae) was the most widely used. The beetle populations using $M$. micrantha were observed widely on Java (see Fujiyama et al. 2013, for further information), Sumatra (Lampung, Padang and Lake Toba), Borneo (Balikpapan and Pontianak in Kalimantan, Kinabaru in Saba), and Kuala Lumpur. In Kuching in Sarawak, in addition, feeding traces were found on this plant although no individual was collected. In Sulawesi, by contrast, the populations using M. micrantha were found in rather restricted areas of the southern lowland (Siwa and Tinokari), but not in the northern part (Manado and the vicinities). No population was from M. micrantha in Lombok. Some beetle populations also occurred on Mikania sp. aff. cordata (Burm. F.) B. L. Robinson at high altitudes (approximately $>600 \mathrm{~m}$ altitude) in Java (e.g. Mt Gede, Mt Halimun and Mt Salak in the western part), Bali and southern Sulawesi (Palopo). In Sri Lanka, H. diekei was collected on Mikania scandens B. L. Rob.

The following plants were used in restricted areas.

Leucas lavandulifolia: Infestation of $\mathrm{H}$. diekei was found only in west and central Java, although this plant was sporadically found in other regions, such as 
west Sumatra (Padang), east Borneo (Balikpapan) and south Thailand (in the Malay Peninsula).

Leucas mollisima: Found only at Purwodadi Botanic Garden in East Java.

Leucas sp.: Found only at the foot of Mt Rinjani in Lombok.

Plectranthus spp. (this genus was previously assigned as Coleus, Grayer et al. 2010): In Sulawesi, $H$. diekei was found infesting wild and cultivated Plectranthus plants in the northern and southern parts such as Manado, Palopo and Rantepao (Figure 2). In other regions, Plectranthus plants were also commonly observed, but $H$. diekei was not observed on this plant.

Dicliptera sp.: Infestation by $\mathrm{H}$. diekei only at Patuha, West Java (Figure 2).

\section{Morphological analysis}

Six body-size-related characters were measured for a total of 67 females and 67 males from seven populations at six localities in four major islands of Indonesia (see Figure 2): three populations from Mikania micrantha (Bogor, Balikpapan and Tinokari), two from Leucas spp. (Bogor and Lombok), and one population from each of Dicliptera sp. (Patuha) and Plectranthus spp. (Rantepao). Of these, two populations from Bogor, West Java, one from Mikania and the other from Leucas occurred side by side; i.e. they were sympatric. All characters were highly variable among and within populations (Table 1). In the principal component analysis, PC1 occupied $64.7 \%$ of the total variance, and PC2 occupied 14\% (Table 2). Body and elytra length showed high factor loadings to PC1, and elytra height showed a high loading to PC2 (Table 2). The seven populations were not clearly discriminated by PC1 and PC2 (see Supplementary material, Fig. S1). Hence, we simply compared body length and elytral height across populations for the representatives of PC1 and PC2, respectively (Figure 3).

Body length was significantly variable among populations in females ( $\mathrm{df}=6$, $\mathrm{F}=2.624, P=0.025$ ) but not in males (df $=6, \mathrm{~F}=0.837, P=0.546$ ) (Figure 4). Females of the Balikpapan population had much smaller bodies than other populations. On the other hand, elytra height was variable among populations both in females ( $\mathrm{df}=6, \mathrm{~F}=5.589, P<0.001$ ) and in males ( $\mathrm{df}=6, \mathrm{~F}=7.462, P<0.001$ ) (Figure 5), whereas host use seemed to be unrelated to this morphological divergence (Table 3, Figures 4, 5). In summary, there was a certain morphological divergence among populations specifically in the elytra height for both sexes, but there was no clear morphological distinction among populations with respect to geographic or ecological divergence.

There were significant among-population differences in the number of hairs on the penis guide ( $\mathrm{df}=6$, Kruskal-Wallis $X^{2}=38.127, P<0.001$ ) and the types of apical edge of penis ( $\mathrm{df}=6$, Kruskal-Wallis $X^{2}=54.121, P<0.001$ ). Specifically for the latter, there seemed to be a geographic divergence; i.e. populations from Java and Kalimantan, and those from Sulawesi and Lombok. The former population group possessed the emarginate (Type I) structure more frequently, whereas the latter population group possessed the convex (Type III) structure more frequently (Figure 6). The intermediate, truncate (Type II) structure was found in both population groups (see Figure 6). Here 


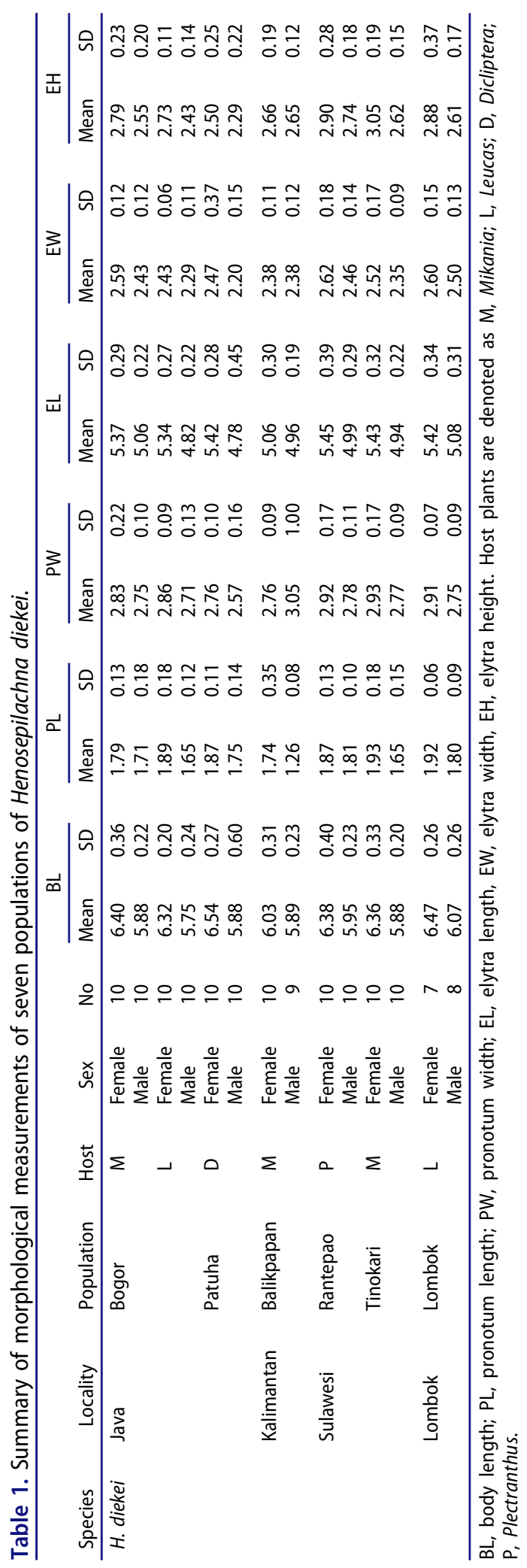


Table 2. Summary of principal component analysis using six morphological measurements in seven populations of Henosepilachna diekei.

\begin{tabular}{lcc}
\hline Factor & \multicolumn{2}{c}{ Component } \\
\hline Importance of components & PC1 & PC2 \\
Standard deviation & 0.666 & 0.310 \\
Proportion of variance & 0.647 & 0.140 \\
$\quad$ Cumulative proportion & 0.647 & 0.787 \\
Factor loadings & & \\
Body length (BL) & 0.683 & 0.159 \\
Pronotum length (PL) & 0.170 & - \\
Pronotum width (PW) & 0.184 & -0.197 \\
Elytra length (EL) & 0.638 & 0.143 \\
Elytra width (EW) & 0.198 & -0.139 \\
Elytra height (EH) & 0.155 & -0.945 \\
\hline
\end{tabular}

again, host utilization seemed unrelated to this morphological divergence (Table 3 , Figures 5,6).

\section{Discussion}

The present study showed that Henosepilachna diekei is distributed widely in South East and South Asia, ranging from the Philippines through the Greater Sunda Islands, the western part of the Lesser Sundas, the southern part of the Malay Peninsula, to Sri Lanka. It also appeared that this species uses various plants belonging to Asteraceae, Lamiaceae and Acanthaceae. At the population level, however, this species is monophagous, i.e. each population depends on a single or some closely-related plant species. In consequence, two different populations that depend on different host plants sometimes occur in the proximity. For example, we observed that two populations, one depending on M. micrantha and the other on L. lavandulifolia, occurred side by side in Bogor, West Java. Our laboratory and field-cage experiments revealed that each of these two populations has a very strict host preference to its original plant, M. micrantha or L. lavandulifolia, and there is no reproductive isolation between these two populations except differential host specialization (Fujiyama et al. 2001; Matsubayashi et al. 2011, 2013a, 2013b). In our preliminary studies (K. Matsubayashi et al. unpublished), it was shown that beetle populations collected from other plant species also showed very strict preference for the original plants Hence, $\mathrm{H}$. diekei seems to be in the process of radiation in South East Asia in association with the host plant shift.

It is uncertain which plants the ancestral $H$. dikei population used. At least, M. micrantha, a most widely used plant, and M. scandens, a plant used in Sri Lanka, are not ancestral host plants, because they were recently introduced to South East Asia from South America (Kostermans et al. 1987; Whitten et al. 1996) or North America. On the other hand, the original distributions of other host plants, Mikania sp. aff. cordata, Leucas, Dicliptera and Plectranthus species are still unclear. The speciation and colonization histories of these host plants should be studied. 

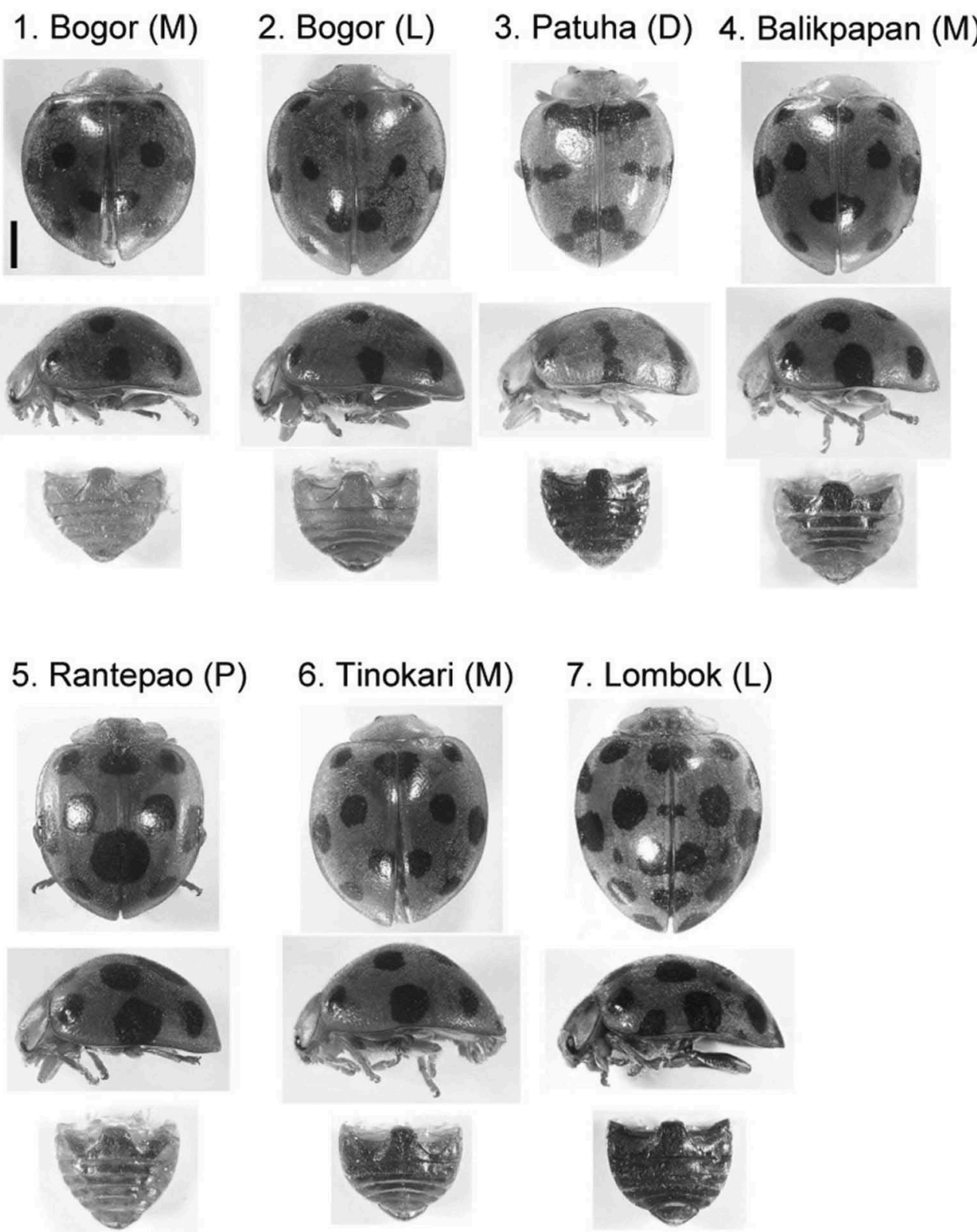

Figure 3. Variation of the elytral pattern and abdominal melanism of Henosepilachna diekei. Dorsal view (top) and lateral view (middle) of habitus and ventral view of abdomen (bottom) in male specimens collected in Java (1-3), Kalimantan (4), Sulawesi $(5,6)$ and Lombok (7). Localities of collection were shown upper of each picture, and the host plants are denoted in the parentheses as M; Mikania, L; Leucas, A; Asystacea, C; "Coleus". Scale bar $=1 \mathrm{~mm}$.

Henosepilachna diekei exhibited geographic variation among populations in elytral height, number of hairs on the penis guide, and the types of apical edge of penis. According to the present morphological analysis, specifically for the types of 
A

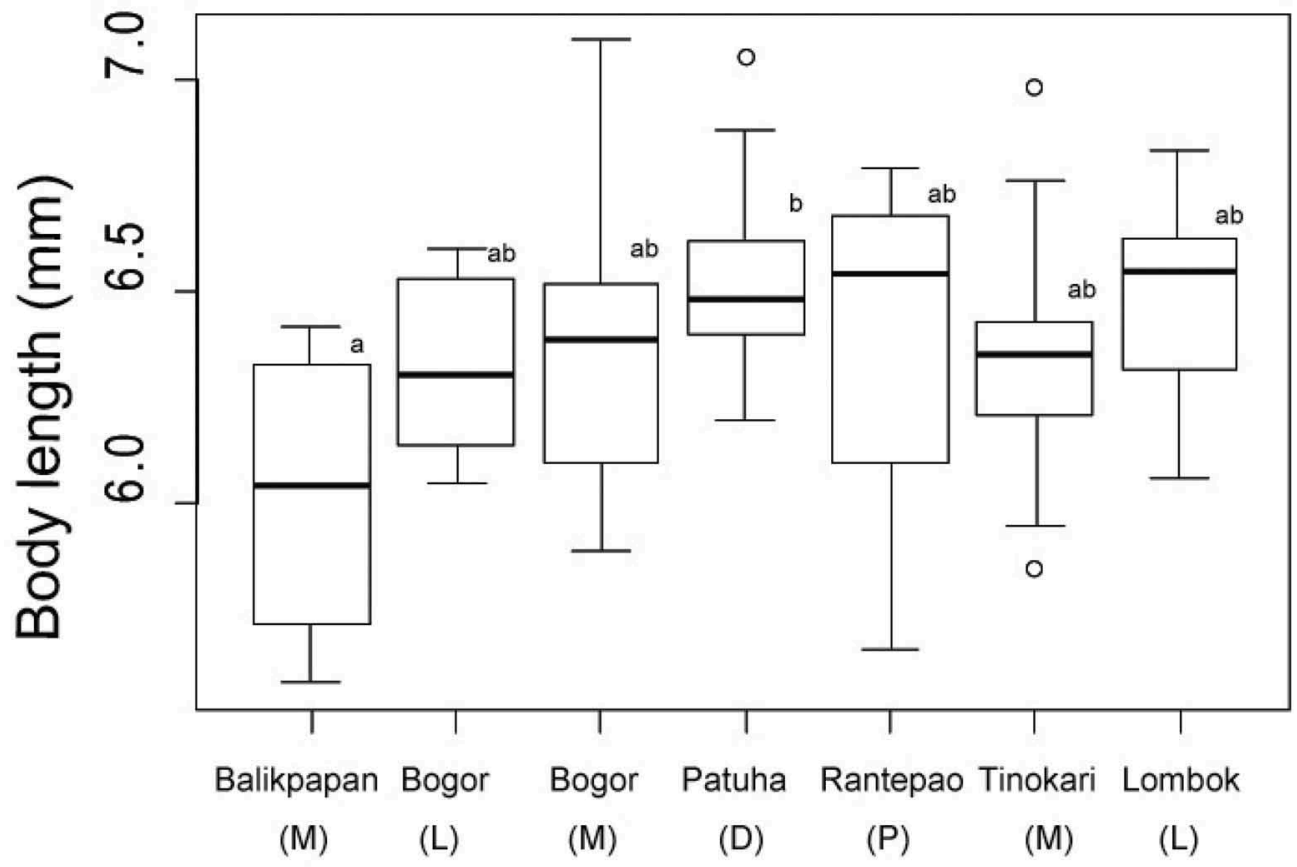

B

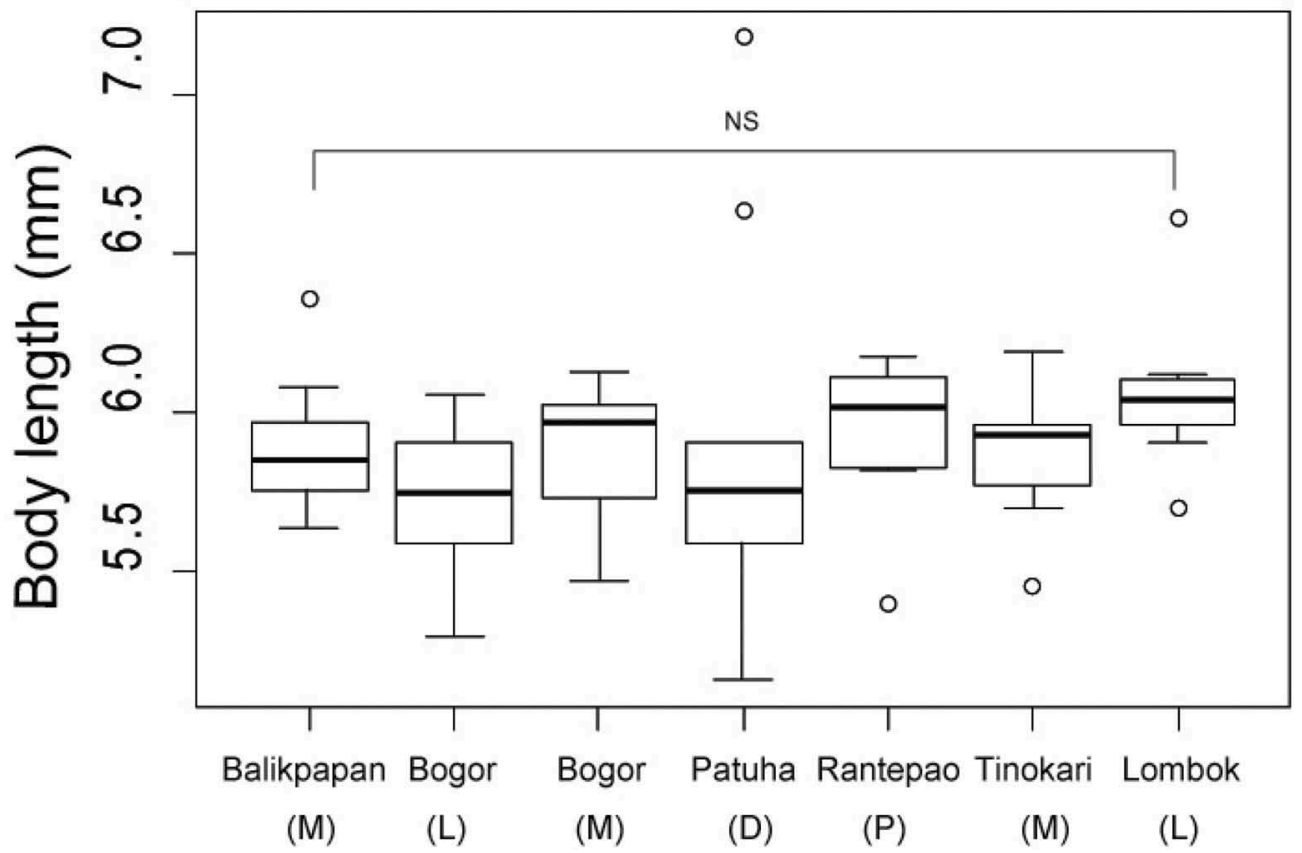

Figure 4. Body length of seven populations of Henosepilachna diekei. (A) Females; (B) males. The host plants were denoted in the parentheses as M; Mikania, L; Leucas, D; Dicliptera, P; Plectranthus. The different letter on the right shoulder of each box indicates significant difference $(P<0.05)$ after adjustment of $P$-value for multiple comparisons (NS, $P \geq 0.05$ ). 
A

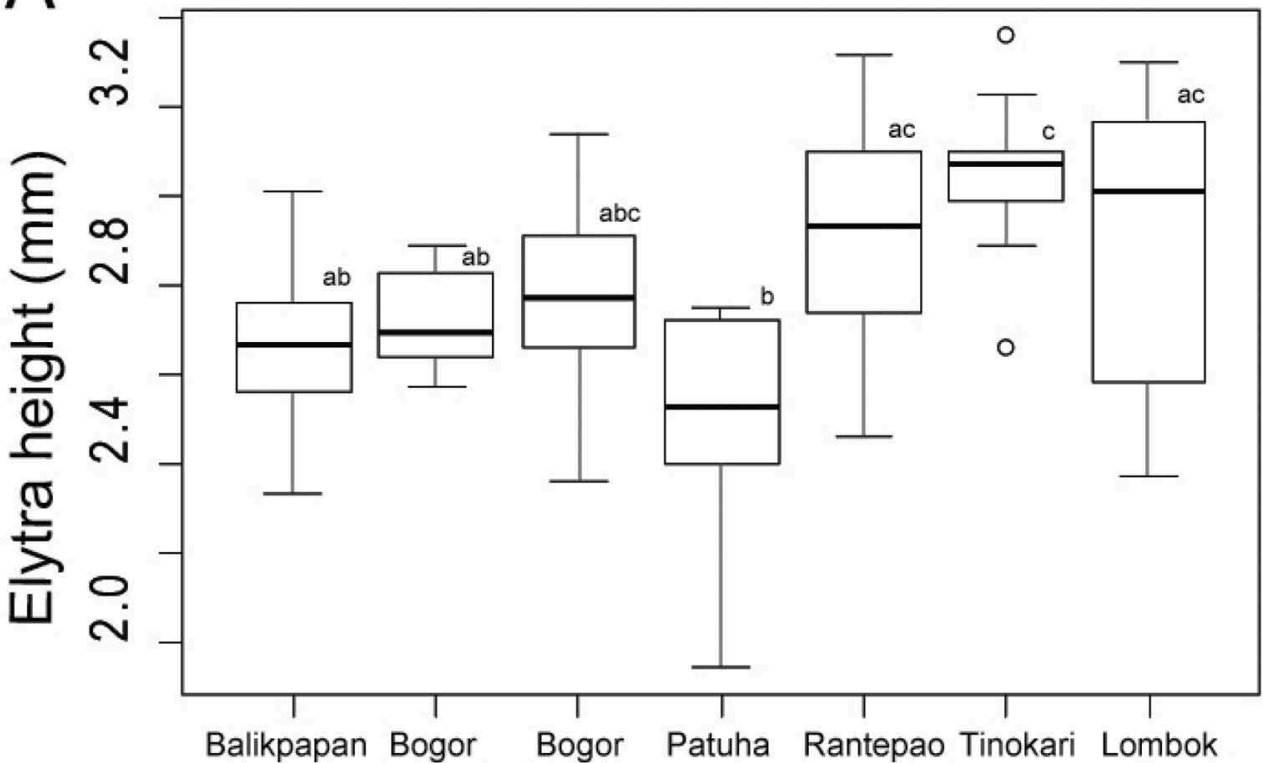
(M)
$(\mathrm{L})$
(M)
(D)
(P)
(M)
$(\mathrm{L})$

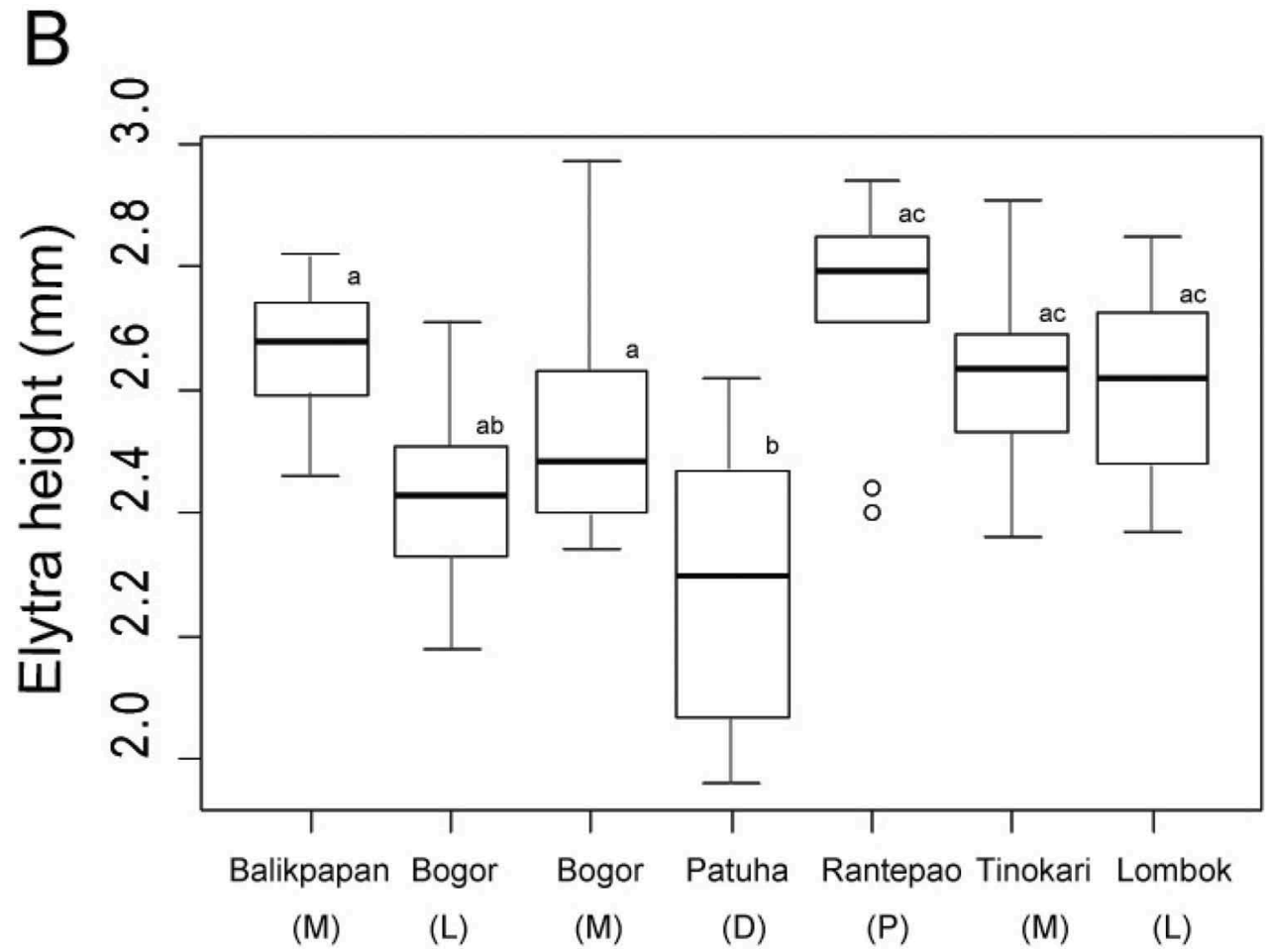

Figure 5. Elytra height of seven populations of Henosepilachna diekei. (A) Females; (B) males. The host plants were denoted in the parentheses as M, Mikania; L, Leucas; D, Dicliptera; P, Plectranthus. The different letter on the right shoulder of each box indicates significant difference $(P<0.05)$ after adjustment of $P$-value for multiple comparisons (NS, $P \geq 0.05$ ). 
Table 3. Number of hairs on penis guide in seven populations of Henosepilachna diekei.

\begin{tabular}{|c|c|c|c|c|c|c|c|c|}
\hline No. hair & Locality & Population & Host plant & $\mathrm{N}$ & Mean & Median & SD & Difference \\
\hline \multirow[t]{7}{*}{ H. diekei } & Java & Bogor & $M$ & 10 & 6.80 & 6.50 & 3.43 & $a b$ \\
\hline & & & $\mathrm{L}$ & 10 & 3.10 & 3.00 & 3.14 & $a b$ \\
\hline & & Patuha & D & 10 & 1.70 & 2.00 & 1.34 & $\mathrm{a}$ \\
\hline & Kalimantan & Balikpapan & $M$ & 13 & 8.23 & 8.00 & 2.05 & $b$ \\
\hline & Sulawesi & Rantepao & $P$ & 10 & 1.50 & 0.50 & 2.22 & $a$ \\
\hline & & Tinokari & $M$ & 10 & 1.30 & 1.50 & 1.06 & a \\
\hline & Lombok & Lombok & $\mathrm{L}$ & 8 & 3.00 & 3.00 & 3.12 & $a b$ \\
\hline
\end{tabular}

Host plants are denoted as M, Mikania; L, Leucas; D, Dicliptera; P, Plectranthus. The significant differences are indicated as different letter $(P<0.05)$ after adjustment of $p$-value for multiple comparisons.

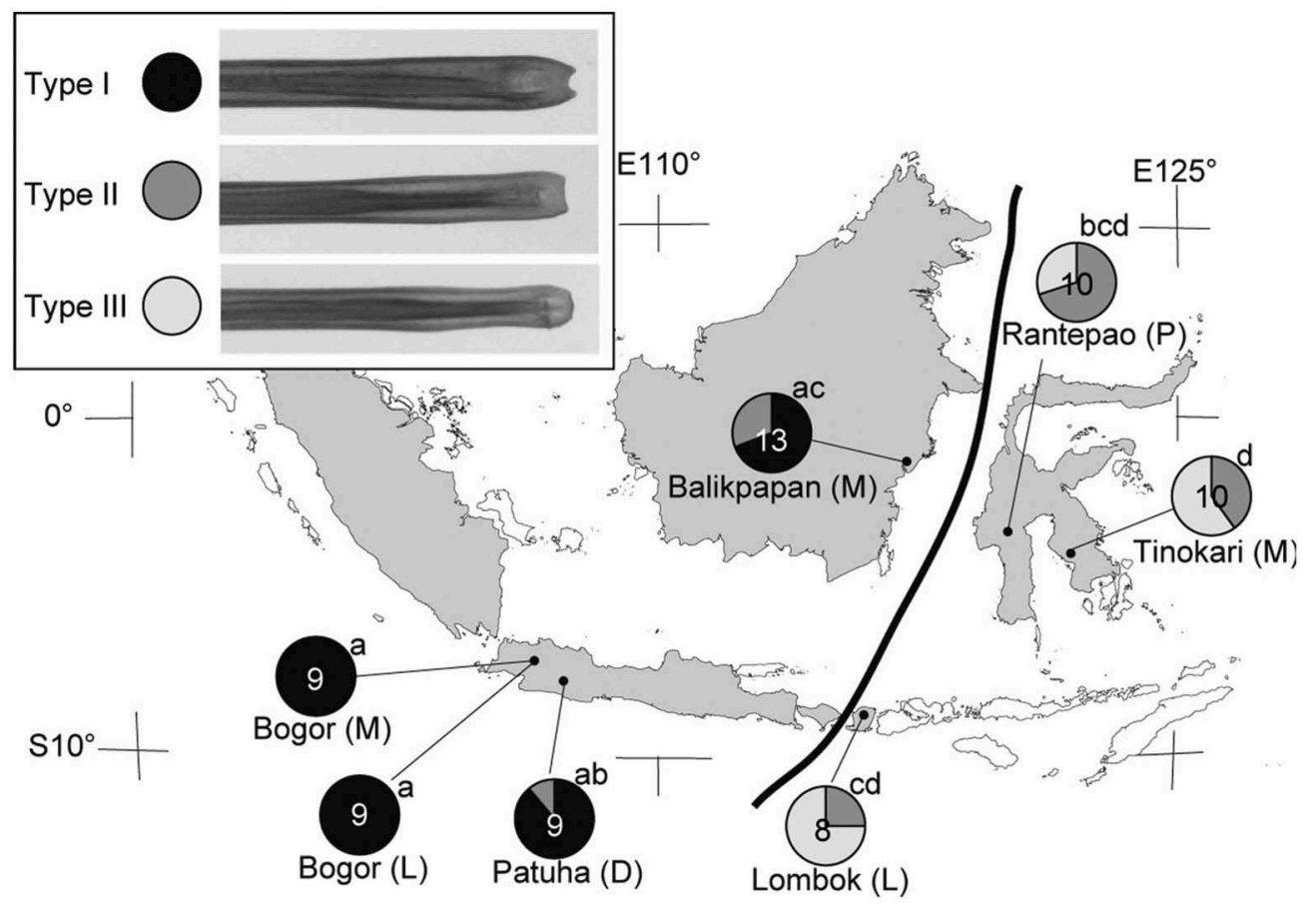

Figure 6. Variation in the structure of apical edge of penis in males of the seven populations of Henosepilachna diekei. Type I, emarginate (filled symbol); Type II, truncate (dark grey symbol); Type III, convex (light grey symbol). Solid line denotes the Wallace line. The number in each pie chart shows the number of specimen. The host plants were shown in the parentheses as $M$, Mikania; L, Leucas; D, Dicliptera; P, Plectranthus. The different letter on the right shoulder of each box indicates significant difference $(P<0.05)$ after adjustment of $P$-value for multiple comparisons.

apical edge of penis, these seven populations were grouped into two, one including four populations from Java and Kalimantan and the other including three populations from Sulawesi and Lombok (Figure 6). In addition, males from Bali (10 individuals), Padang in Sumatra (four individuals) and Sri Lanka (two individuals) possessed emarginate or truncate apical edge of penis, a characteristic of the former 
group. Hence, it seems that the two population groups of $H$. diekei are separated by the Wallace line (c.f. Stelbrink et al. 2012; see Figure 6). In our preliminary molecular phylogenetic analysis, it has also been shown that $H$. diekei populations from the east side of this line and those from the west side form distinct clusters (Matsubayashi 2008; Matsubayashi et al. unpublished data).The Wallace line is assumed to act as a barrier for dispersal in $\mathrm{H}$. diekei populations, as this line acts as a barrier for movements of large animals (Tänzler et al. 2014; Barley et al. 2015). On the other hand, this line seemed not to affect the evolution of host plant use since diversification in host utilization was commonly found in areas to both the east and west of the Wallace line (Figure 2). Further population sampling and detailed phylogenetic work are necessary to provide a comprehensive scheme for the evolutionary history of diversification in the morphological characters and host plant utilization in this beetle species.

\section{Acknowledgements}

The Ministry for Research and Technology, Indonesia (RISTEK) and Research Centre for Biology, Indonesian Institute of Science (LIPI) permitted us to conduct this study in Indonesia. We thank M.T. Kimura for providing valuable comments on the early draft of the manuscript; W.A. Noerdjito, R. Ubaidillah, D. Dwibadra, M.B. Lakim, K. Kitayama and S. Kikuta for field and laboratory support; S. Nakano, N. Kobayashi, T. Katoh, Y. Ohta for helpful advice during the experiment; Sarino and Gianto for assistance in field collection and laboratory experiments in Indonesia; and C. Saengkhong and P. Kaewprasertsri for field assistance in Thailand.

\section{Disclosure statement}

No potential conflict of interest was reported by the authors.

\section{Funding}

This study was supported by Grants-in-Aid from the Japan Society for the Promotion of Science to H. Katakura (Nos. 14204081, 18207005, 23405012) and by the 21st Century Centre of Excellence (COE) Program on 'Neo-Science of Natural History' (Program Leader: Dr H. Okada) at Hokkaido University, financed by the Ministry of Education, Science, Sports, Culture, and Technology of Japan, and also by the Japan Society for the Promotion of Young Scientist to K. Matsubayashi (No. 10J03106).

\section{References}

Barley AJ, Datta-Roy A, Karanth KP, Brown RM. 2015. Sun skink diversification across the IndianSoutheast Asian biogeographical interface. J Biogeogr. 42:292-304.

Brown WD. 1990. Size-assortative mating in the blister beetle Lytta magister (Coleoptera: Meloidae) is due to male and female preference for larger mates. Anim Behav. 40:901-909.

Dieke GH. 1947. Ladybeetles of the genus Epilachna (sens. lat.) in Asia, Europe, and Australia. Smiths Misc Coll Washington DC. 106:1-183.

Drés $M$, Mallet J. 2002. Host races in plant-feeding insects and their importance in sympatric speciation. Philos Trans R Soc Lond B. 357:471-492. 
Fujiyama N, Ueno H, Kahono S, Hartini S, Matsubayashi KW, Kobayashi N, Katakura H. 2013. Distribution and differentiation of Henosepilachna diekei (Coleoptera: Coccinellidae) on two host-plant species across Java, Indonesia. Ann Entomol Soc Am. 106:741-752.

Fujiyama N, Ueno H, Kahono S, Katakura H. 2001. Preliminary experiments on adult food preference of the Indonesian phytophagous ladybird beetle. Epilachna sp. aff. emarginata (Coleoptera: Coccinellidae). Entomol Sci. 4:35-37.

Gould SJ, Woodruff DS. 1990. History as a cause of area effects: an illustration from Cerion on Great Inagua, Bahamas. Biol J Linnean Soc. 40:67-98.

Grayer RJ, Eckert MR, Lever A, Veitch NC, Kite GC, Paton AJ. 2010. Distribution of exudate flavonoids in the genus Plectranthus. Biochem Syst Ecol. 38:335-341.

Hadley A. 2010. CombineZP [Internet; cited 2014 Jun 15]. Available from: http://www.hadleyweb. pwp.blueyonder.co.uk/.

Jadwiszczak A, Węgrzynowicz P. 2003. World catalogue of Coccinellidae. Part I-Epilachninae. Olsztyn: Mantis; 264p.

Jiang Y, Bolnick DI, Kirkpatrick M. 2013. Assortative mating in animals. Am Nat. 181:E125-E138.

Katakura H, Nakano S, Kahono S, Abbas I, Nakamura K. 2001. Epilachnine ladybird beetles (Coleoptera, Coccinellidae) of Sumatra and Java. Tropics. 10:325-352.

Kobayashi N, Ohta Y, Katoh T, Kahono S, Hartini S, Katakura H. 2009. Molecular phylogenetic analysis of three groups of Asian epilachnine ladybird beetles recognized by the female internal reproductive organs and modes of sperm transfer. J Nat Hist. 431:637-1649.

Kostermans AJG, Wirjahardja S, Dekker RJ. 1987. The weeds: description, ecology and control. In: Soerjani M, Kostermans AJG, Tjitrosoepomo G, editor. Weeds of rice in Indonesia. Jakarta: Balai Pustaka; p. 24-565.

Masly JP. 2012. 170 Years of "Lock-and-Key": genital morphology and reproductive isolation. Int J Evol Biol. 2012:1-10.

Matsubayashi KW. 2008. Role of ecological divergence for speciation process in phytophagous ladybird beetles of the genus Henosepilachna [Ph.D. dissertation]. Sapporo: Hokkaido University.

Matsubayashi KW, Kahono S, Katakura H. 2013a. Divergent host plant preference causes assortative mating between sympatric host races of Henosepilachna diekei ladybird beetle. Biol J Linnean Soc. 110:606-614.

Matsubayashi KW, Kahono S, Hartini S, Katakura H. 2013b. Micro-spatial and seasonal distributions of two sympatric host races of the phytophagous ladybird beetle Henosepilachna diekei (Coleoptera: Coccinellidae) and their host plants in West Java, Indonesia. Treubia. 40:9-24.

Matsubayashi KW, Kahono S, Katakura H. 2011. Divergent host plant specialization as the critical driving force in speciation between populations of a phytophagous ladybird beetle. J Evol Biol. 24:1421-1432.

R Development Core Team R. 2012. A language and environment for statistical computing. Vienna: R Foundation for Statistical Computing.

Sota T, Nagata N. 2008. Diversification in a fluctuating island setting: rapid radiation of Ohomopterus ground beetles in the Japanese Islands. Philos Trans Royal Soc B: Biol Sci. 363:3377-3390.

Sota T, Tanabe T. 2010. Multiple speciation events in an arthropod with divergent evolution in sexual morphology. Proc Royal Soc B: Biol Sci. 277:689-696.

Stelbrink B, Albrecht C, Hall R, von Rintelen T. 2012. The biogeography of Sulawesi revisited: is there evidence for a vicariant origin of taxa on Wallace's "anomalous island"? Evolution. 66:2252-2271.

Tänzler R, Toussaint EF, Suhardjono YR, Balke M, Riedel A. 2014. Multiple transgressions of Wallace's Line explain diversity of flightless Trigonopterus weevils on Bali. Proc Royal Soc B: Biol Sci. 281:20132528.

Whitten T, Soeriaatmadja RE, Afiff SA. 1996. The Ecology of Java and Bali. Singapore: Periplus Editions. 